\title{
Participatory Ergonomics: Work Related Musculoskeletal Disorders among Cashew Nut Factory Workers in Karkala Taluka
}

\section{Ruchita H Narsia ${ }^{1 *}$ and Joseph Oliver Raj $^{2}$}

${ }^{1}$ Post Graduate Student, Alva's college of Physiotherapy, Moodbidri, Karnataka, India ${ }^{2} P h D$ Research Scholar, Vinayaka Mission's College of Physiotherapy, Vinayaka Mission's Research Foundation (Deemed to be University), Salem, Tamil Nadu and Professor, Alva's college of Physiotherapy, Moodbidri, Karnataka, India Physiotherapy, Moodbidri, Karnataka, India.

Received: May 09, 2020

Published: May 19, 2020

(C) All rights are reserved by Ruchita $\mathbf{H}$

Narsia and Joseph Oliver Raj.

\begin{abstract}
Background: Musculoskeletal disorders are the most common work-related problems. Cashew nut factory workers have various works like cutting, peeling, grading, packing, and boiling where participants are more prone for the musculoskeletal disorders, which include repetition, contact stress, forceful contraction, awkward and sustained postures [1].

Aim: Formulation and implementation of participatory ergonomic program in order to prevent incidence of Work-Related Musculoskeletal Disorders (WRMSD) among cashew nut factory workers and to determine the effectiveness and benefits of the program in prevention of WRMSDs.

Study Type: Experimental study (Pre-post intervention study).

Material and Methods: 160 subjects were screened in different cashew nut factories in the taluka for WRMSD on the basis of Work Analysis Questionnaire (WAQ). Out of the 160 subjects screened, 58 were selected on the basis of inclusion criteria and using Nordic pain chart further structured interview was done. Pre intervention NPRS was taken. Intervention was given for 3 months and again the follow up was taken.

Results: Using paired ' $t$ ' test it was seen that the mean value was $1.22 \pm .795$ (SD) and the significance value was ( $p<0.001)$ which shows that there was a significant reduction in the pain intensity (NPRS) of the 58 subjects to whom the intervention was provided. Conclusion: Participatory Ergonomics (PE) is beneficial in reducing the risk as well as work related musculoskeletal disorders and their pain. As PE is a low-cost program, it can be used in a very effective way to reduce the number of sick leaves and it also helps in increasing the work productivity of the workers.

Keywords: Participatory Ergonomics; Work Related Musculoskeletal Disorder; Numeric Pain Rating Scale; Work Analysis Questionnaire
\end{abstract}

\section{Abbreviations}

PE: Participatory Ergonomics; NPRS: Numeric Pain Rating Scale; WAQ: Work Analysis Questionnaire; WRMSD: Work Related Musculoskeletal Disorder; SD: Standard Deviation; WfH: Work for Health

\section{Introduction}

In a community set up musculoskeletal disorders are the most common work-related problems. They are cumulative disorders which results from repeated exposure to high or low intensity loads for prolonged period of time and due to which various regions get affected such as neck, back, upper limbs and lower limbs [1].

Cashew nut factory workers have various works like cutting, peeling, grading, packing, and boiling. All these activities are more prone to risk factors for the musculoskeletal disorders, which include repetition, contact stress, forceful contraction, awkward and sustained postures [1]. The prevalence rate for pain in lower back and neck among cashew nut factory workers is $28.5 \%$ [1]. Low back pain (LBP) and neck pain (NP) are major public health problems which increases the costs for individuals, companies and society [2]. To prevent WRMSD injuries at workplace, ergonomic interventions are provided.

One standard definition of ergonomics, "fitting the work to the worker" encompasses not only physical work demands but also mental demands, the social environment, psychological impact, and organizational features of the workplace. Ergonomics is sometimes framed, as optimization of the physical dimensions of workstations, tools and equipment, lifting tasks and static loads. Never- 
theless, it is not only limited to those job-level considerations of physical task features, but sometimes called "micro ergonomics" or "hardware ergonomics" [3-16].

With the merits of ergonomic interventions, there are demerits such as high cost and poor adherence.

Participatory ergonomics (PE) is a program in which the workers and management come together and participate in preventing the work-related musculoskeletal disorders at the workplace [3]. There are few obstacles or barriers for the implementation of participatory ergonomics which are as follows- lack of worker participation or interest, lack of a clear mandate, lack of management support, budget and time constraints. PE can be viewed as a targeted approach which helps in injury prevention and enhances the ease of workers' participation [14-20].

\section{Objective of the Study}

So, the objectives of the study were:

- To formulate and implement participatory ergonomic program in order to prevent incidence of WRMSDs among cashew nut workers.

- For determining the effectiveness and benefits of the program in prevention of WRMSDs.

\section{Materials and Methods}

These are the inclusion and exclusion criteria for this study, followed by methodology.

\section{Inclusion criteria}

- Cashew nut factory workers with any one or more work related musculoskeletal disorders.

- $\quad$ Sick leaves for more than a week due to any WRMSDs in past 3 months.

\section{Exclusion criteria}

- Medically diagnosed cardio-pulmonary, metabolic or systemic diseases.

- Pregnant women.

- Any neurological deficit.

- Any recent surgeries in the past 6 months.

- Persons with any referred pain.

- Ethical clearance was taken from the Institutional Ethical Review Board of Alva's college of Physiotherapy.
Phase-1: Formulation and validation of questionnaire and education material

A Workplace Analysis Questionnaire (WAQ) was formulated after a detailed evaluation of workers and worksite at cashew factories. The analysis included physical workload, psycho-social workload, general health status, sick leave and productivity. The WAQ was given for content validation to 4 experts in the field of Orthopaedic Rehabilitation and Ergonomics.

Based on the workplace and worker evaluation a tailor-made education material, Work-for-Health (WfH) was formulated. The WfH included audio-visual training and pamphlets.

Phase-2: Factory selection and recruitment of participants

A list of total number of cashew nut factories available in Karkala Taluk (Karnataka, India) was obtained from the Town Municipal Council. The factory selection was done randomly. Later, the participants were selected conveniently and recruited.

\section{Phase-3: Intervention}

After recruiting the participants, the study was explained and written consent was taken. They were assessed for their pain on the basis of Nordic Questionnaire and a structured interview was conducted, by the investigator. A meeting was held with the workers and management. Leaders were selected on the basis of their qualities like leadership, boldness, management skills and motivation. Workers were given information on the risk factors of work-related musculoskeletal disorders and how to prevent them.

The workers were advised for worksite wellness program as well as lifestyle modifications. They were given ergonomic modifications, from the resources available at the workplace. So that they can inform, motivate, and instruct the group to follow the same. This will help them to learn about the PE and prevent the risk of WRMSDs. In this study we managed these barriers as follows: for lack of participation or interest of workers, we provided them pamphlets and educated them and the management about the real need of preventing injuries at workplace.

To avoid conflicts with their job duties, we had short sessions like micro breaks in between their job shifts. To solve the budget and time constraints we went to their workplace and provided our interventions. To manage lack of management support, distributed flyers and educate the workers and as well as the management about the participatory ergonomics and its need at workplace.

At the end of the 3 months intervention, they were given materials which included pamphlets and posters. After, the 3 months of intervention, follow up was taken with the help of Nordic Questionnaire. 


\section{Results and Discussion}

The statistical analysis of the study was done using SPSS version 20. For this study the statistical test used was paired ' $\mathrm{t}$ ' test. It was used to compare the pre and post NPRS values in the same number of subjects. Descriptive statistics was used to find out the mean and the standard deviation for the age of the subjects and the result was that the mean value was $1.22 \pm 0.795$ (SD) and the significance value was $(\mathrm{p}<0.001)$ which shows that there was a significant reduction in the pain intensity (NPRS) of the 58 subjects for whom the intervention was provided.

The purpose of this study was to assess the work-related musculoskeletal disorders and to provide appropriate measures to reduce the risk related to the particular work. So, to assess this problem total 160 subjects were taken from cashew nut factories. All the subjects were given the consent form which was translated into local language. A WAQ was given to all the subjects which was translated into the local kannada language. Out of that, 58 subjects complained of various musculoskeletal pain. So out of $100 \%$ it is found that $36.25 \%$ people complained of work-related musculoskeletal pain. Out of those subjects who complained of pain $74.1 \%$ had backache, $27.5 \%$ had knee pain, $6.8 \%$ had heel pain, 3.4\% had hip and shoulder pain, followed by $1.7 \%$ for neck and elbow pain. Those 58 subjects were then further assessed for musculoskeletal pain on the basis of Nordic questionnaire and a structured interview was taken by the investigator. The NPRS pre values were taken. After that, intervention to the subjects was given with the help of leaders and management who actively participated in our intervention. The intervention consisted of exercises and stretches for their respective joint pain, before starting their work shift and in their micro brakes. They were also taught ergonomic modifications and were asked to follow the same. The intervention time was of 03 months and after that post intervention values of NPRS were again assessed with the help of Nordic questionnaire. For statistical analysis, paired ' $t$ ' test was done which showed there was a significant difference $(p=0.001)$ in the PRE_NPRS values and POST_NPRS values. This shows that the subjects had pain relief which not only helped them in increasing the work productivity but also helped in reducing their sick leaves.

\section{Conclusion}

Participatory Ergonomics (PE) is beneficial in reducing the risk as well as work related musculoskeletal disorders and their pain. As PE is low cost program, it can be used in a very effective way to reduce the number of sick leaves and it also helps in increasing the work productivity of the workers. The need to formulate PE is to create awareness among the workers about the hazards of faulty postures of carrying loads and teaching them the correct way of handling loads with the help of the ergonomic advices and by doing modifications of their surroundings. It was concluded that Par-

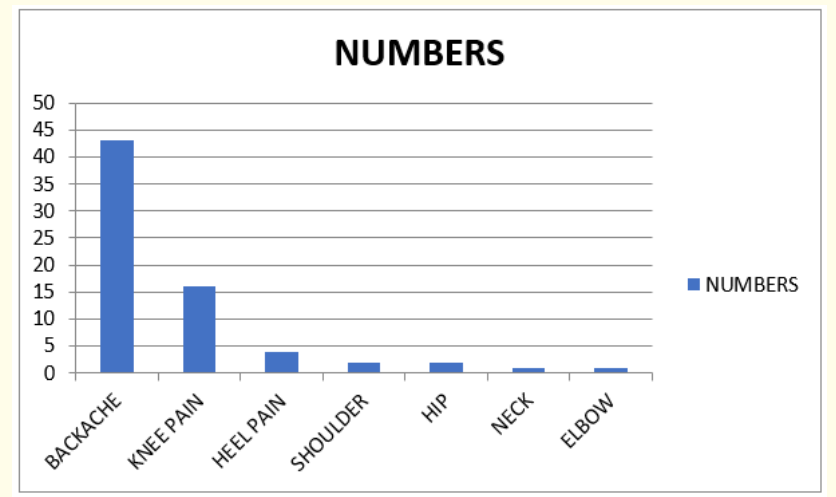

Figure 1: Maximum WRMSD problems according to area wise in an individual.

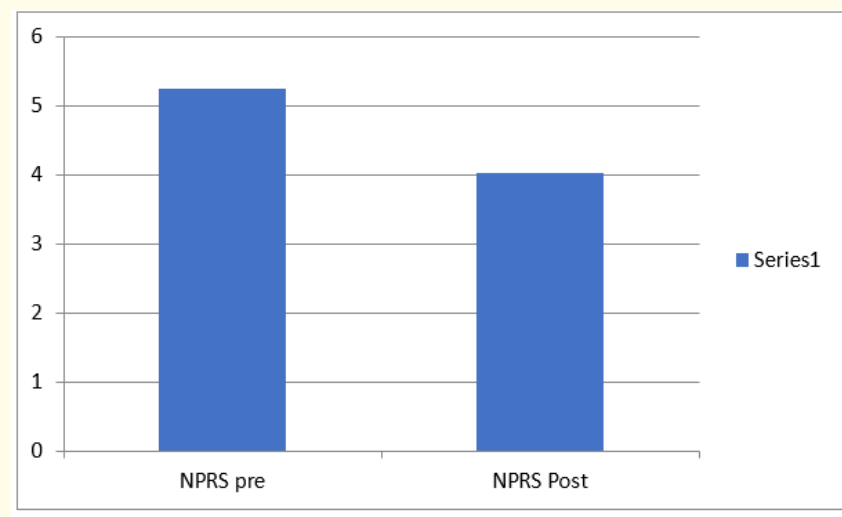

Figure 2: Pre and post NPRS values.

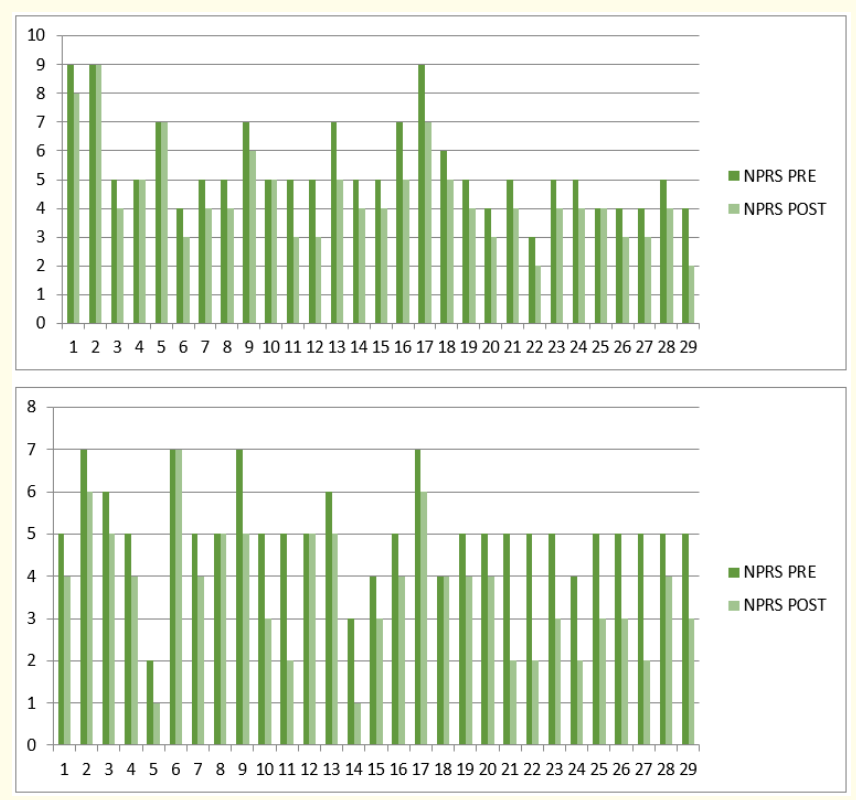

Figure 3: Showing the PRE and POST values after intervention period including follow up. 

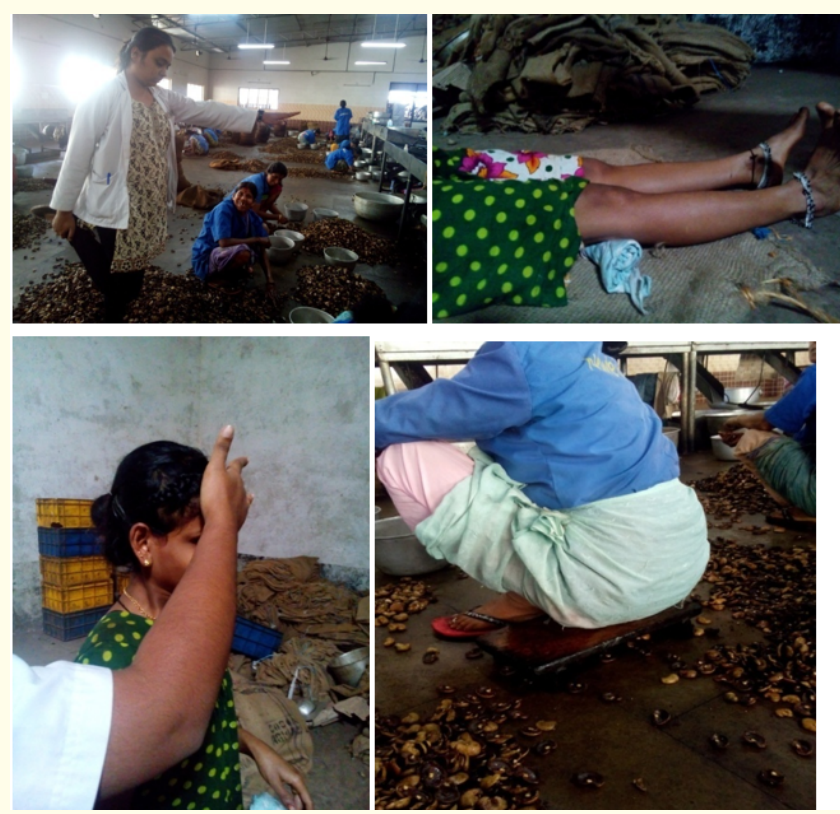

Figure 4: Photographs of intervention in different departments of a cashew nut factory..

ticipatory Ergonomics can improve risk factors related to WRMSD and it is effective for atleast small scale industries.

\section{Conflict of Interest}

We declare that there was no financial aid given and there was no conflict of interest while we were carrying out this study.

\section{Acknowledgement}

We are thankful to the other team members without whose guidance and support this study would not have been possible. $\mathrm{Dr}$ Siddhi Pradha Mahopatra, lecturer at Alva's college of Phyiostherapy and Dr Mukesh Sinha, lecturer at Alva's college of Physiotherapy under whom statistical analysis was done.

\section{Bibliography}

1. N Girish., et al. "Prevalence of musculoskeletal disorders among cashew nut factory workers". Archives of Environmental and Occupational Health 67 (2012): 37-42.

2. Drissen T., et al. "Stay@Work: Participatory Ergonomics to prevent low back and neck pain among workers: design of a randomised controlled trial to evaluate the (cost-) effectiveness". BMC Musculoskeletal Disorders 9 (2008):145.

3. Participatory Ergonomics Fast Fact, Public Service Health and Safety Association (PSHSA), Ontario, (2010).

4. Morgan D. "Participatory Ergonomics: Introducing the OSACH Ergonomic programme Implementation Continuum (EPIC) program". The Safe Angle 11 (2009).
5. Driessen M., et al. "Economic evaluation of a Participatory Ergonomics programme to prevent low back and neck pain". Work 41 (2012): 2315-2320.

6. Driessen MT., et al. "What are possible barriers and Facilitators to implementation of Participatory Ergonomic programme". Implementation Science 5 (2010): 64.

7. Drissen MT., et al. "Process evaluation of a Participatory Ergonomic programme to prevent low back pain and neck pain among workers". Implementation Science 5 (2010): 65.

8. Henning R., et al. "Workplace Health Protection and Promotion through Participatory Ergonomics: An Integrated Approach". Public Health Reports 124 (2009).

9. Kogi K. "Advances in participatory occupational health aimed at good practices in small enterprises and the informal sector". Industrial Health 44 (2006): 31-34.

10. Cantley LF., et al. "Effect of systematic ergonomic hazard identification and control implementation on musculoskeletal disorder and injury risk". Scandinavian Journal of Work, Environment and Health 40.1 (2014): 57-65.

11. Van der Beek AJ., et al. "European guidelines for prevention in low back pain, chapter2”. European Spine Journal 15.2 (2006): S136-S138.

12. Sell L., et al. "A Tailored Learning Program for Prevention of Musculoskeletal Disorders". Journal of Ergonomics S4 (2014): 002.

13. Baumann Andrea., et al. "The Ergonomic Program Implementation Continuum (EPIC): Integration of health and safety - A process evaluation in the healthcare sector". Journal of Safety Research 43 (2012): 205-213.

14. Ludeke C., et al. "A randomized controlled trial of integrated care to reduce disability from chronic low back pain in working and private life". British Medical Journal 340 (2010): c1035.

15. Loisel P., et al. "Implementation of a participatory ergonomics program in rehabilitation of workers suffering from subacute back pain". Applied Ergonomics 32 (2001): 53-60.

16. Punnett L., et al. "Participatory ergonomics as a model for integrated programs to prevent chronic disease". Journal of Occupational and Environmental Medicine 55.12 (2013).

17. Carrivick PJ., et al. "Evaluating the effectiveness of a participatory ergonomics approach in reducing the risk and severity of injuries from manual handling”. Ergonomics 48.8 (2005): 907914. 
18. Rivillis I., et al. "Evaluation of a participatory ergonomic intervention aimed at improving musculoskeletal health". American Journal of Industrial Medicine 49.10 (2006): 801-810.

19. Straker L., et al. "A Randomized and controlled trial of a participative ergonomic intervention to reduce injuries associated with manual task: Physical risk and legislative compliance ergonomics 47.2 (2004): 166-188.

20. Redway S., et al. "Photo voice in work place to identify health and safety hazards and promote workplace change". American Journal of Industrial Medicine 53 (2010): 1150-1158.

\section{Assets from publication with us}

- Prompt Acknowledgement after receiving the article

- Thorough Double blinded peer review

- Rapid Publication

- Issue of Publication Certificate

- High visibility of your Published work

Website: https://www.actascientific.com/

Submit Article: https://www.actascientific.com/submission.php Email us: editor@actascientific.com

Contact us: +919182824667 